\title{
LAS “ALGUACÍAS” MÁS ANTIGUAS EN LOS MANUSCRITOS DE OCAÑA (TOLEDO)
}

\author{
Carmen A. Martínez Albarracín y \\ Joaquina Albarracín Navarro
}

Entre los manuscritos en lengua romance, descubiertos en Ocaña (Toledo) en el año $1969^{1}$ se encuentran dos libros escritos en lengua castellana toledana que usaban los mudéjares.

El término alguacía lo encontramos en textos aljamiados. Así en J. Ribera y M. Asín², pág. 311, alguacía 'el encargo', en cambio en textos romances no aljamiados, como son las Leyes de Moros castellanas del siglo XIV3, figuran las formas alguacé 'albacea o fiador de una transacción comercial' y como variante alguacé. Como es sabido, la forma castellana albacea, escrito alvacea, se registra ya en documento toledano de 1205, Corominas, DCELC, I, pág. $81^{4}$. El étimo árabe al-wasìya 'cosa encargada en testamento, de la raíz wasà 'encargar', 'hacer testamento'. El término abstracto árabe wasiya, figura en Freytag, IV ${ }^{5}$, pág. 475; véase Dozy, Supplements, II, pág. $815 a^{6}$. La forma alguacía con el significado de 'precepto, encargo', nos ofrece,pues, primera documentación en el habla toledana de finales del XIV.

1. Juan Martínez Ruiz y Joaquina Albarracín NAVARro, «Libros árabes, aljamiado-mudéjares y bilingües descubiertos en Ocaña (Toledo)», en Revista de Filología Española, LV, 1972, pp. 63-64; Joaquina Albarracín NAVARro y Juan MARTíneZ RuIZ, "Glosas aljamiadas romances en un manuscrito árabe inédito de Ocaña (Toledo)», XVI Congreso Internacional de Lingüística y Filología Románicas, Palma de Mallorca, 1980; Juan MARTínez RUiz y Joaquina ALBARRACÍN NAVARRO, «Farmacopea en La Celestina y en un manuscrito árabe de Ocaña», en Actas del I Congreso Internacional sobre la Celestina, Barcelona, pp. 409-425; Joaquina ALBARRACín NAVARRO, «El sello de Salomón en uno de los manuscritos árabes inéditos de Ocaña (Toledo)», I Congreso Internacional de las Tres Culturas, Toledo, 1983, pp. 105-115.

2. J. Ribera y M. Asín, Manuscritos árabes y aljamiados de la Biblioteca de la Junta, Madrid, 1912.

3. Memorial Histórico Español, V, Madrid, 1853, pp. 205 y 208.

4. Joan Corominas, Diccionario Crítico Etimológico de la Lengua Castellana, Madrid, 1954, 4 vols.

5. Georg Wilhelm FreYTAG, Lexico Arabigo-Latinum, 4 vols., Halle, 1830-1837.

6. R. DozY, Suppléments aux Dictionnaires Arabes, 2 vols., Leyden, 1881. 
La forma albacea con el WAW árabe reproducido por B y no por GU, según es normal en castellano, la explica Corominas, loc. cit., por entrada tardía de dicho vocablo en el castellano común, se podría también explicar dicha diferenciación por motivos semánticos para evitar la confusión entre dos términos del mismo étimo árabe. De todas formas, todavía en el siglo XVI, el zamorano Dr. Villalobos, cita albaceha entre las palabras moriscas con que "los toledanos ensucian la palideza de la lengua castellana".

Estas alguacías, en el sentido de 'consejos', 'encargos' de los manuscritos de Ocaña son copia de otros manuscritos más antiguos, y probablemente son traducciones de textos árabes, conservan su escritura y lengua árabe en el nombre de Allāh, comienzos de suras y expresiones coránicas.

Uno de los libros de Ocaña es el mejor conservado, aunque acéfalo, ya ha sido estudiado ${ }^{7}$. Las páginas son de papel de algodón grueso, escritura gótica tardía, tinta de lana tamaño $22,15 \mathrm{~cm}$. Solamente quedan unas hojas sueltas que son los folios $17 \mathrm{v}, 18 \mathrm{r}$ y $18 \mathrm{v}$ que están en estudio.

El otro libro es en la actualidad, un conjunto de hojas sueltas en mal estado de conservación, parece ser que faltan bastantes, pero a pesar de esto hemos podido agruparlas en tres apartados:

A) Parecen las más antiguas, en el castellano lleva de vez en cuando frases escritas en lengua árabe y con el alifato.

B) Las hojas sueltas van ordenadas con números romanos.

C) Escritas en castellano solamente.

Vamos a ocuparnos del apartado A) Hojas sueltas escritas en castellano con frases intercaladas en lengua árabe con grafemas árabes y a continuación la traducción anteponiendo "Que quiere dezir"...

Dada la diversidad de consejos hemos creído conveniente clasificarlos por materias:

1. Lectura coránica. F.9r.1-3. Quien leyere la açora de as-samā wa at-tarīq (LXXXVI 1) quando se echare a dormir...

Quien leyere tabaraka ... en el Corán tabāraka aparece en las azoras (VII, 52 XXV, 1,11,62, LV,78 y LXVII, 1). En el sentido de '¡Bendito sea!'.

2. Normas de conducta. Podemos dividirlas a su vez en: Moral, higiene y relaciones matrimoniales.

\subsection{Moral}

-F. 6r. 9-13. Guarte posar cabo los muertos, que ellos no nombra Allāh sy non en lo que atañe al mundo, dixo ¿Quién son los muertos? ¡O mensajero

7. Joaquina Albarracín Navarro, «Unas "alguacías" de Ocaña (Toledo), en el marco de convivencia de las tres Culturas», Actas del II Congreso Internacional Encuentro de las tres culturas (Toledo 1983), Toledo, 1985, Tomo II, pp. 165-178; id., "Toledano medieval e hispanoárabe en unas alguacías mudéjares de Ocaña (Toledo)», II Congreso de Historia de la Lengua Española, Madrid, 1992, pp. 917-929. 
de Allah! Dixo, los rricos, que son la conpaña deste mundo, que tienen sus coraçones en él, estos son los perdidos.

-F. 6r. 13-17. Sey sabio e deçiplo, e pregunta por tu ley, e non seas como dixo Allăh e dixo el anabi, la salvaçión sea sobre él, que el que non sabe nyn aprende, nyn demanda a los sabios por su ley, está y es perdido.

-F. 6v. 23-26. Non aconpañes al bevedor del vyno que es maldito, e será penado, nyn aconpañes al que non quiere pagar el azaque, que será llamado en el poderío de los cielos enemigo de Allāh.

-F. 7r. 12-14. Quien coje a otro a soldada e non le paga, abaxa Allāh su obra, e yo seré su acusador.

-F. 7r. 25-28. Non crio Alläh testalmiento como la lengua, que por ello entrará la persona en el aljana, e por ello entrará en gihanam por ende aprisiónala que es perro rrabioso.

-F. 10v. 5-6. Guarte del mençojero que en el aljana non ay mençojeros.

-F. 10v. 6-15. Guarte del azine que ay en ello seis males, tres en este mundo e tres en el otro. Los tres de este mundo que presara la muerte e destruye el arrisque e desafuzia la riqueza, e las tres del otro mundo es la prena e la ira del Señor, la turança en el fuego.

-F. 10v. 15-22. Guarda esta alguaçia ca Gibril ma mortró e me castigó con ella, la salvaçión de Allāh sea sobre él, e dixo ya Aly yā 'A $A\lceil$ tú eres comigo como era com Muça, salvo que después de mí non hay anabi e yo te castigo oy con esta alguaçia la qual sy guardaras cunplieras serás loado e morrás cayahyd e rebivarte a Allāh el día del juyzio al faqui e sabio.

-F. 11r. 6-8. Non syguas plazer nin gozo que non cata a los gozosos e más sigue la tristeza e el lloro que Allăh ama al triste.

-F. 11r. 15-17. Sey de justo pagado que Allăh ama a los que son asy.

-F. 11r. 17-23. Guarte de la hazalejería que la hazalejería es como el fuego en la leña e la hazalejería (papel roto) ley es más estendida sobre mi alma que el movimiento de la ormiga en el cuerpo prieto e en la noche estará la hazalejería, es la descreencia menos menor porque dixo Alläh el Alto quien tiene fuzia de parecer ante Allāh fará buenas obras e non ponga aparçero con Allăh.

-F. 12v. 11.12. Demanda menester al de cara pagada e son vergonçosos que dado bien asta en la xoguença.

-F. 12v. 12-16. Los que demandan al mundo aquello que an menester cerca lo neçesario e non más, éstos tales pasarán la puente del Açirate como el relámpago presuroso e es Allāh de ellos pagado e non sañoso.

-F. 12v. 18-20. Quien da de comer al muçlim fasta que sea farto escrevirele ante Allāh mill gualardones e perdonarle a Allāh mill pecados.

-F. 13v. 15-18. Darás açalem a quien encontrares de los muçlimes e escrivirte an a ti por cada açalem treynta alhaçanas quando será el syervo en 
los aprietos de la muerte sus coyunturas darán açalem unas a otras, así el caballo blanco sobre el prieto.

-F. 13v. 27-30. Faz buen debdo a tu pariente aunque te faga mal debdo porná Allah bendiçión en tu vida e endereçarte a tu ley ca el que faze mal debdo a su pariente es mal de ti por dicho de Allāh que dixo ataja es a vosotros.

\subsection{Higiene} penado.

-F. 6v. 23-25. Non aconpañes al bebedor del vyno que es maldito e será

-F. 6v. 25-26. Nin comas al logro que el que lo come guerreale Allah.

-F. 9v. 5-6. Come con tres dedos que el axaytán come con dos.

-F. 10v. 1-2- Come el azeyte e úntate con ello e non se te açercará el axaytán. Desayúnate con la sal cada mañana ca ello ay melezina para setenta enfermedades de la primera es la lepra e el abaras.

-F. 11r. 12-15. Non te mondes los dientes con palo de arrayhan nin de granado que en cada palo de ellos ay tacha más usa fregar la boca con nuez que por ello hay veynte e quatro alfadilas en el cuerpo e en la ley.

-F. 12v. 6-9. Muncho dormir amata el coraçón e acarrea olvidança, e muncho reyr amata el coraçón e quita claridad de la cara e muchos pecados endureçen el coraçón e trae la arrepentençia quando non aprovecha. Sigue la astenençia que non hay cosa amarga como la pobreza.

-F. 13r. 3-11. Quien come lo helel apura su alma e adelgaza su alma e su coraçón e lloran sus ojos de Allah e non está aprtado del, e quien come lo dubdoso está en su ley dubdoso e adolma su coraçón, e quien come lo haram muere su coraçón e çerçena su ley e enflaqueçerrenydad e non oye Allah su rrogaria.

\subsection{Relaciones matrimoniales}

-F. 17r. 23-29. Duerme con tu muger en la noche del lunes e será la criatura leedor e la noche del martes será la criatura farta e contenta e la noche del jueves antes de adohar será la criatura sabia que fará buenas obras e fuyrá el axaytán de él, e la noche del viernes será de buena vida puramente e obedeçerá a Allá e el día del viernes será la criatura de buena ventura e morrá en fi çabily lahy.

-F. 17v. 1-4. Cuando te naçiera fijo di la el alyca que es el levantar el açala e con esto non le dañará el axaytán.

-F. 18v. 1-3. Quando entrares con tu novia descalçala e lava sus pies e derrama el agua por los rrincones de casa e meterá Allăh en tu casa bendiçión e piedad.

-F. 18v. 3-7. Manda a la novia que non coma en los syete días de la boda vinagre nyn leche nyn culantro nyn mançanas agras porque estas cosas viedan el engendramiento e viedan la flor. 
-F. 18v. 8-10. Quando entrares con tu novia atrae tu mano por su cabeça e lee el açora de ida waqa'ati.

-F. 18v. 16. ida waqa'ati e lewa elahukum fasta jalidīna e di: Señor dame en arrizar de ella fijos buenos que cunplan tus mandamientos e se desanparen a ti, e dame con ella buena abenençia e muncho arrizaque de helel, que tú eres oidor e sabio e sy asy lo fizieres darte a Allăh de ella tanto bien e arrizaque que non lo puedes saber otro saber sy non Allāh.

-F. 18v. 17-19. Non te ayuntes con tu mujer fasta que digas: bismi Allahhi el-rahman el rahim que quiere dezir: en el nonbre de Diod el piadoso de las gentes el piadoso de los creyentes e sy non lo dixeras el diablo será aparçero en los fijos que obieres.

-F. 18v. 20-22. Non fables quando durmyeres con tu muger sy non esto faría que fuese muda la criatura que entonces se engendrase.

-F. 18v. 22-25. Non duermas con tu mujer estando sañosa sy non esto faría ser desobediente la criatura que engendrase e albaracada e tiñosa.

-F. 18v. 26-28. Non duermas con tu muger so árbol que lleva fruto e que tenga fruta porque la criatura que ally se engendrase sería femenina de los que pareçen a las mugeres en sus maneras.

\section{Oración}

-F. 6r. 20-22. Faz complidamente tu alguado e demanda perdón a Allah, e non gastes muncha agua. Quien fará açala sobre Muhamad e después de su alguado que diga: Allahumma salā Muhamad wa 'alā āā Muhamad. Que quiere dezir: Apiade Allah sobre Muhamad e sobre los de Muhamad, esparçiará Allāh su coraçón e oirá su rogaria.

-F. 6r. 26-30. Guarada el açala de adohar en camino o en villa, que al día del juyzio oyrán que dirán ençima de las alturas del aljana, o fazedores del açala de adohar, entrad en el aljama e avras tanto gualardón como

-F. 6v. 1-19. Como ay fueses al-hây a la cademe non tiene cobdiçia de fazer açala con el aljama ay non el mal creyente falso, encubierto aborreçido de Allăh. Da açala con el aljama es ante Allăh como el açala de las almalaycas en el çielo segundo e ve tenprano a la açala porque fagas açala en el açafe primero que es ante Allah como los açafes de las almalaycas. Quando quisyeres alguna cosa rruega a tu señor que te escosga lo mejor e después contentate con lo que te fuere escojido, e serás de los bianaventurados es este mundo e en el otro.

Quien menoscaba a la açala e la apocare menoscabarle a Allāh en los alcançamientos de gusanos de gihanam. Faz çobhe quando esclareçiere e alayxi después de puesto el sol quanto durare ordeñare una rres e detarda el. çahor que aquello es de las obras de los profetas e de los buenos, asy me castigó Gabril, la salvación sea sobre él. 
-F. 6v. 20-23. El syervo es amado quando está en su açajda que quiere dezir: Señor, yo fiz mal e adolme mi alma, por ende demandote perdón que non ay perdonador synon tú.

-F. 7r. 5-12. Quando fizieres açala, tiende tus manos en derecho de tus pechos, e non las alçes en derecho de tu cabeça e rresponderá Allah a tu rrogaria, nin leas rrezio en tu rrogaria, nin sea fecha de rrezu ante la gente porque aquello lleva el açala de la gente. Desque paresca la ora del açala aparejate luego para ella e guarte non te ocupe el axaytan, e quando te viniere a la voluntad el bien fazae non lo detardes ay non el axaytan te lo quitará de la voluntad.

-F. 7v. 4-16. Quien dixere cada día veynte e çinco vezes (renglón sin escribir) que quiere dezir: Demando perdón a Allah por my e por mi padre e por todos los muçlimes e muçlimas e creyentes e creyentas, los bivos dellos e los muertos escrevirle an de los çercanos de Allah e de los buenos servydores. Quien dixere cada día dies vezes (espacio en blanco) que quiere dezir estas palabras non ay otro señor sy non Allāh ante toda cosa e non ay otro señor sy non Allăh después de toda cosa non ay otro señor sy non Alläh, el firme, el estable para syempre jamás nuestro señor Allah, El feneçera a toda cosa alcançará en gualardón por dezir estas palabras non quedará almalayca en el çielo que non demande perdón para él sesenta myll vezes. Quien dixere cada día veynte vezes (espacio en blanco) Que quiere dezir estas palabras Señor pon bendiçión sobre mí en la ora de my muerte e después de my muerte alcançará por gualardón que non le tome Allah cuenta de sus pecados el día que ... mades a las gentes por las graçias que vinieren.

-F. 9r. 10-26. Quando te acostares demanda perdón a Allāh e faz açala sobre my e di: subhana Allah wa bihamdihi wa là ilaha ilă Allăh wa Alläh akbar wa hawlà wa lā quwata ilä billlāhi il' aliyu el- 'azì $m$ que quiere dizir estas palabras: Bendito sea Allāh e loado sea Allăh e non ay señor synon Alläh e Allāh es el mayor e non ay mouimyento e fuerza sy non en Allăh el alto e el alto e el grande. Cuando vieres la luna dirás tres vezes: lā ilaha ilä Allāh wa Allāhu akbar, que quiere dezir: non ay otro señor synon Allāh e Allāh es el mayor. Quando te acaeçiere algún fecho grande di: Señor yo te demando por la honra de Muhamad e de los de Muhamad, que me muestres e me apiades más piadoso de los piadosos, e dixo ya Aly quien son los tuyos o mensajero de Allāh dixo todo bueno. Non entres en la cama fasta que digas: Señor yo te demando del bien que es en ella e defiendome contigo del mal que es.

- F. 9v. 1. en ella.

-F. 9v. 26-30. façer las çinco açalaes en el aljama. Cada día que amaneçe en el mundo castiga el día al omme omme e le dize: fijo de Adam yo soy día nuevo e te castigo sobre tu obra, por ende mira lo que fazes entre tu día e la noche así mesmo.

-F. 12v. Al que faze Allāh alguna graçia e la agradeçe quando alguna trebulança le viene, e es paçiente quando engaña la voluntad e peca, éste tal entrará en el aljana por qualquiera puerta que quisyere. 
-18-20. E quien da a comer al muçlim fasta que sea farto escrevirele an ante Allāh myll gualardones e perdonale a Allăh myll pecados.

-F.12r. 1-9. Qieren dezir estas palabras, loado sea Allāh ante toda cosa e loado sea Allăh después de toda cosa, e loado sea Allāh el firme durante por syempre es nuestro señor, él feneçerá a toda cosa e loado sea Allāh en toda guisa. Quien fará açala sobre Muhamad çien vezes cada día que diga cada vez Alhuma șalā 'alā Muhamad wa 'ala elā Muhamad, que quieren dezir estas palabras Señor apiada sobre Mehamad e quien las dixere perteneçela alcançarla rrogaria la rrogaria el día del juyzio.

-F. 12r. 21-25. Faz açala de noche syquiere quanto durare en ordeñar una res que dar arracas de dentro de la noche es mejor que myll de día. El que fiziere açala de noche es el que tiene mejor cara de día.

-F. 12v. 23-28. Cuando dixeres Allāhu akbar para fazer la açala lançarás las manos e espaçe entre tus dedos e alça tus manos e onbros e quando arracares por tus manos en derecho de tus rrodillas e tus dedos llegados e quando estuvieres en pie ley en tu açala e pon tu mano derecha sobre tu ysquierda en tus...

-F. 13v. 23-27. Quando loares a ti en tu casa dirás Señor pon mejor de lo que piensan e non me prendas con lo que dizen, perdóname con lo que non saben e con esto vencerás al axaytán para qur te pagues de ti.

\section{Prácticas religiosas}

-F. 7r. 1-4. Ayuna el mes de arramadán con seys días del mes de xaagual escrevirle an tanto gualardón como sy ayunase todo el tiempo.

-14-17. Sabe que por syete bienes que son al omme cobdiçio Gibril, la salvaçión sea sobre él, cobdiçioso de los ommes fazer las çinco açalaes con el aljama e con el alfaquí e posarse cabo los sabios...

-28-31. Ayuna los días blancos que son en cada luna, el terzeno o el catorzeno o el quinzeno, e enblanqueçerá Allāh la cara del que los ayunare el día del juyzio e averá tanto gualardón como sy ayunase.

\section{Religión}

-F. 6r. 4-8. Quando te honrrare Allah con quatro cosas, non te falleçerá nada, que uses veda en tu fabla, e guardes las encomendanças, e seas franco de alma e fanbriento de vientre.

-F. 6r. 8-9. Busca los bienes de Allāh lo halel deve todo muçlim.

-F. 7v. 1-4. Quien sirve a Alläh syn saber e syn entender a donde (papel roto) la adoba, es como el ciego que anda por el campo syn adestrador, entre cardos e piedras.

-F. 10r. 1-5. El mal creyente se pareçe en tres cosas, usa la mentira en sus razones e quebranta la promesa que promete e engaña al que en él se enfía e non le aprovecha el castigo. 
-F. 12r. 9-17. La ley es la que desengaña Allāh al mensajero e a los muçlimes. Ya Aly yā 'Ali la ley es toda xoguençia que guarda la cabeça e los sentidos que son en ellos que son de pecar, los ojos e los oydos e la lengua e el vientre que entiendese lo del vientre lo que nos manda guardar del aziner e de comer lo vedado, es comer lo vedado comer lo demasiado que también lo pone la ley por haram comer las otras viandas que pone la ley por haram.

-F. 12r. 17-18. Las cabeças del juiçio de Allāh es el callar salvo en nonbrar a Alläh que es el bien todo.

-F. 12r. 18-21. Seys cosas son de parte del axaytan, el bostezar el gomytar el escopir e la sangre de las matrizes e el estornudar e el sueño en al majid.

-F. 12r. 27-28. El muncho demandar perdón es fuerte castillo para defender del fuego a los arrepentidos.

-F. 12v. 20-22. Allāh judga sobre sus syervos los que quiere por ende quien se contenta para El es la contentaçión e quien se ensaña para El es la saña.

-F. 12v. 23-28. Quando dixeres Allähu Akbar para fazer açala lançarás las manos e onbros e quando arracares por tu manos en derecho de tus rodillas e tus dedos llegados a quando estuvieres en pie ley en tu açala e pon tu mano derecha sobre tu ysquierda en tus...

-F. 13r. 11-16. Quando se ensaña Allāh da su syervo dale arrizque e algo de haram e quando se enfortaleçe su saña con él dos axaytanes que se lo sacasen e le aparten de la ley e ponga su coraçón en el mundo e tiene en poco el pecado diziendo Allăh es el Perdonador Pyadoso.

-F. 13r. 16-30. Quando ama Alläh al syervo de tarda su rogaria e dizen las almalaycas Señor responde a tu syervo el qreyente. Dize Allāh el alto, dexad a mi syervo ca non soes vosotros mas piadosos que yo, ya respondía a su rogaria e a su omillaçión que yo soy sabidor con él.

Ya Aly yā'Ali por ventura muere el creyente e non es conprado su menester a él es como el que llamó a las gentes a buen camino de guiamiento él e los otros que lo siguen, con él alcançará gualardón de buen con él alcançará gualardón de buen gramyento e buen camino e de quantos lo paguen e non mengüe cosa del gualardón.

Ya Aly y $\bar{a}$ 'Ali toda persona que guía a los creyentes a mal camino o a lo vedado de Allăh, a él estrucen los pecados de los que fizieren e non reçibe Allăh el açala syn atahor nin açadaca de mala parte ganada. Ya Aly, non hay arrepentençia al arrepentido fasta que alympie su vientre de lo haram e adobe su mantenimiento de halel.

-F. 13v. 3-7. Da açacadas por tus muertos que Allāh tiene puestas almalaycas que percarán e lyevan las açadacas de los bivos e de los muertos, e toman plazer con ellos e dizen: Señor, perdona a quien nos esclareçió nuestros coraçones e da açadacas por nosotros e albriçialos con el aljana. 
-F. 13v. 8-14. En el día del juyzio mandará Allah que quando çierra las puertas de ella çierre las puertas de la aljana e tornalos el fuego e çércalos a el fuego de cada parte, dize: Señor, sy los metieras antes en el fuego, antes que nos açercaras tu piadad e dirá Allăh asy lo quise yo, fazer con vosotros porque bevísteis en haram e me guerreásteis con los pecados grandes.

-F. 13v. 18-23. Quando dieres açadacas de lo mejor ganado que en tu poder obiere que un bocado de lo bien ganado e un dátil es más amado Allāh que myll doblas después de tu muerte.

\section{Vicios y virtudes}

-F. 6r. 1-4. Non averguençes nyn rretaygas nyn blasfemes de otro que non ay carne syn tacha e non se remyde el pecado del maldezir e blasfemear fasta que pidan perdón aquellos que dixeron mal del o le perdone.

-9-13. Guarte de posarte cabo los muertos, que ellos non nonbram Allāh sy non en lo que atañe al mundo, dixo quién son los muertos (?) o mensajero de Alläh. Dixo, los rricos que son la conpaña deste mundo que tienen sus coraçones en él, estos son los perdidos.

-13-17. Sey sabio e deçiplo, e pregunta por tu ley e non seas como dixo Allāh e dixo el anabi, la salvaçión sea sobre él, que el que non sabe nyn aprende nyn demanda a los sabios por su ley, este es perdido.

$-17-20$. Malo es el amigo que descubre tu secreto e dize lo malo de ti non a bien (hueco roto) vezino que encubre tus buenas obras e descubre tus malas, e non a bien en mujer que cobdiçia quitarse de su marido.

-F. 7r. 12-13. Quien coje a otro a soldada e non le paga, abaxa Alläh su obra e yo seré su acusador.

-21-24. Quando llora el guérfano entremaçese el alorxe de Allah, e dize Allăh a Gibril: Yo faré llorar en el fuego a quien faze llorar al guérfano e ensancharé en el aljana el lugar de aquel que le faga reyr.

-25-28. Non crió Allah testalmiento como la lengua, que por ello entrará la persona en el aljana, e por ello entrará en gihanam por ende aprisyonalo que es perro rravioso.

-F. 8r. 1-3. El cadiq se pareçe en tres cosas, adobar lo que es entre él e entre Allah con fazer buenas obras e quiere para la gente lo que quiere para sy.

-3-7. El temeroso se pareçe en tres cosas guardarse de posarse en el lugar sospechoso e guardarse en el lugar sospechoso e guardarse de mentir e guardarse de maldedezer e de masturar e dexar la mytad de lo halal por miedo de lo haram.

$-8-10$. El pecador se pareçe en tres cosas, trascuerdase e sigue los juegos e olvídase e sigue los plazeres.

$-10-12$. El duro se pareçe en tres cosas, non apiada al flaco, non nyn se contentan con lo poco, nyn le aprovecha el castigo.

-13-16. El verdadero se pareçe en tres cosas, encubre al servyçio y syrve al cryador e encubre al açadaca e encubre su almoçiba que es mas que sy onre en su façienda e en su cuerpo. 
-16-18. El malo se pareçe en tres cosas, a ma el mal de los syervos de Allāh e apartase del buen camino.

-18-20. El dañador se pareçe en tres cosas, es dañador a sus veçinos e es desobediente al criador e tiene en sy muchas maldades en sy.

-21-23. El que tiene olvidado Allāh se pareçe en tres cosas, fabla muncho e jura munchas juras myntirosas e descobrir a los vecinos.

-23-26. Los syervos de Allăh se pareçen en tres cosas, aborreçen los malos e aborreçen los apetitos de la voluntad por amor de Allahh.

-27-29. El purificado en el servyçio de Allah se pareçe en tres cosas el algo e los onores de las gentes e aborreçe el muncho fablar.

-F. 8v. 1-3. El franco se pareçe en tres cosas, dar pasada a la gente e perdonar después que a lugar e poder para se vengar e para el azaque e gasta el algo en dar açadacas.

-4-6. Las señales del escaso son tres, myedo de pobreza e desvia de sy a quien le demanda e envía lo vazío e non faze bien a las gentes nyn a su alma.

-7-8. Pareçe el medro en tres cosas eprantanos del coraçon e muncho espanto e miedo.

-8-11. Pareçese en tres cosas el sufriente, sufrir los trabajos en servyçio de Alläh e guardarse de la desobedençia de Allăh e a pasençia cuando corre la ordenança de Allăh contra él.

-12-14. Pareçense los amigos en tres cosas, que pongan por tí su cuerpo e su algo syn tu algo e su pèrsona syn tu persona.

-14-16. El falso se pareçe en tres cosas, faze falsa jura e enga(ña) a las mugeres e da falso testemunio.

-16-18. El descreído se pareçe en tres cosas, duda en la ley de Alläh e haze halel lo que harremó Allāh.

-18-21. El desafuziado se pareçe en tres cosas, asegurarse del mal de Allăh e desafusiarse de la piadad de Allăh e contralla al mensajero de Allăh.

-21-24. El temeroso se pareçe en tres cosas, toma myedo del nombramyento de Allăh e teme la pena de Allāh e es vergonçoso ante las manos.

-23-24. El peor de las gentes es el que tiene larga su vida e su obra mala.

-25-29. El aborreçido de Allāh es el que es temido e honrado de la gente por myedo de su mal, peor que este el que come solo e no da su ayuda e non honra a su guesped, e peor es que este el que honrra al rrico por su rriqueza e menospreçia al menesteroso por su menester e faze (falta un renglón por estar rota la página).

-F. 9v. 1-5. Quando la persona dura quarenta días que non se posa cabe los labios endurezese su coraçón e çiega que non ve el camino bueno para su alma, porque el sabio es vida para las almas e non ay buen xuiçio sy non con el saber e non aprovecha el saber sy non con la obra.

-6-9. Non reçibas el testigos de los grandiosos nyn del que se alquila, e sey piadoso con los syervos e non des bofetadas en cara de ningún vibo sea una bestia e non jures por Allăh en mentira. 
-22-24. Non puede aver foyura el enbidioso nyn le alcança el myntroso nyn honrra el escaso nyn sentençia el de malas costunbres nyn ay amistad al estado.

-F. 10r. 1-5. El mal creyente se pareçe en tres cosas usa la mentira en sus rrazones e quebranta la promesa que promete e engaña al que en él enfía e non le aprovecha el castigo.

-5-8. El perezoso se pareçe en tres cosas vagaroso en la obediençia de fasta que se pierde e falleçe e detarda el açala fasta que sale su ora.

-8-11. El arrepentido se pareçe en tres cosas, apartase de lo haram e es cobdiçioso de buscar el saber e es su entinçión de non tornar al pecado jamás.

-11-13. El sabio se pareçe en tres cosas, andar poco por el mundo e sobrellevar las malas costunbres de las gentes e sofrir las fortalezas en serviçio de Alläh.

-13-16. En el mesurado ay tres señales fazen buen debdo a quien le faze mal debdo e da a quien non le da e non faze rogaria sobre el que le faze syn rrazón.

-16-19. El loco se pareçe en tres cosas manospreçia los mandamientos de Allah e fablar mal nyn nonbrar Allahh e danyficar a los syervos de Alläh.

-19-22. El bienaventurado se pareçe en tres cosas tomar su mantenymyento de mala parte e faze mal a las gentes e non fazer las çinco açalaes. Allăh.

-26-27. El bueno se pareçe en tres cosas aconantarse a la obediençia de

-27-29. El malo se pareçe en tres cosas, fazer el mal a la gente que es obediençia de Alläh e fazer mal a los syervos. (de Alläh).

-F. 10v. 22-25. En el hazalajero ay tres señales, non faze sus arracas e sus açalas conplidas con el faqui e peca en el açala a solas e nonbra a Allāh ante la gente e olvidalo quando está solo.

-26-28. El que es adolmado se pareçe en tres cosas, sogudga a los menores e con rreguridad e come algo dellas e non cata de donde le viene lo haram.

-29-30. El envidioso se pareçe en tres señales, loa a la gentes quando está con ellos e dize mal dellos detrás.

-F. 11r. 3-6. Quando el moço non es temeroso e arrepentido e guardado de lo vedado e non le abasta el castigo de las gentes asy caerá el castigo dél como cae la luvya de la abestuz e del cristal.

-F. 11r. 6-8. Non sygas plazer nyn gozo que non cata a los gozosos e más sigue la tristeza e el lloro que Allăh ama al triste.

-8-11. El que se arrepiente por la donaçión que a fecho e la reboca, es como el que torna a comer lo que gomita e la donaçión del pariente es bastante syn sastifaçión non reboque nynguno su donaçión sy non el padre lo que da al fijo.

-15-17. Sey justo pagado que Allāh ama a los que son asy e quando fizieres bien fazlo por amor de Alläh e quando gastares gasta por amor de Alläh. 
-17-23. Guarte de la hazalejería que la hazalejería es como el fuego en la leña e la hazalejería como ley es más escogida sobre mi alma que el movimyento de la ormiga en el cuerpo prieto, e en la noche estará la hazalejería es la descreençia menos menor porque dixo Allăh, el alto, quien tiene fuzia de parecer ante Allāh fará buenas obras e non ponga aparçero con Allāh.

-F. 12v. 1-2. Guarte de maldezir de tu muçlim nyn a otra cosa alguna que la maldiçión torna al que la dize.

$-2-6$. Al que faze Allah alguna graçia e lo agradeçe quando alguna trebulança le viene e es paçiente quando lengaña la boluntad e peca, este tal entrará en el aljana por qualquiera puerta que quisyere.

$-11-12$. Demanda menester al de cara pagada e son vergonçosos que dado bien está en la xoguença.

-13-16. Los que demandan al mundo aquello que an menester cerca lo necesario e non más estos tales pasarán la puente del açirate como el relámpago presuroso e es Allah de ellos pagado e non sañoso.

-16-18. E los que tienen el mundo por alcançar rriquezas pareçerán ante Allāh el día del juyzio el sañoso sobre ellos.

-20-22. Judga sobre sus syervos los que quiere, por ende quien se contenta para él es la contentaçión a quien se ensaña para él es la saña.

-F. 13v. 1-2. El que usa la mentira escribenle ante Allah por mintroso e el que usa la verdad escrivenle ante Allăh por mintroso e el que usa la verdad escrivenle ante Alläh por verdadero.

-14-18. Darás açalem a quien encontrares de los muçlimes e escrivirte an a ti por cada açalem treynta alhaçanas, quando será el syervo en los aprietos de la muerte sus coyunyuras darán açalem unas a otras asy el cabello banco sobre el prieto.

$-27-30$. Faz buen debdo a tu pariente aunque te faga mal debdo porná Allăh bendiçión en tu vida e endereçarte a tu ley es el que faze mal debdo a su pariente es mal de ti por dicho de Alläh que dixo ataja es a vosotros.

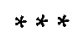

\section{GLOSARIO}

Palabras de origen árabe:

açadaca, 8r.14; 13r.29. Del ár. ș a d a q a 'limosna,donativo'.

açadacas, plu. castellanizado de açadaca. F. 8v. 3; 13v.3; 4,19.

açafe, 6v.7 y açafes, 6v.7. Gay. açafe. Del ár. șaff 'hilera, fila en que se colocan los que concurren a la mezquita.

açafes, plu. cast. de açafe.

açajda, 6v.21. Gay açaxda v. assachda, 'Postración del cuerpo durante la oración'. Del ár. saŷda. 
açala, 6r.28; 6v. 2-3, 4, 5, 6, 11; 7r. 5, 8, 9; 9r.11; 10r. 7; 10v.24; 11v.20; 12r.5,21; 12v.23,27; 13r.29. açalaes, 7 r.16; 10r. 22,25. Plu. cast. de açala, 'oración canónica' del ár. șallà.

açirate, 12v. 14-15. Del ár. șirat gay. 'la puente del, o sea, el puente que debe atravesar el alma del difunto musulmán para poder acceder al paraíso.

açora, 9r. 1; 11r.29. Gay. açora, 'sura o capítulo del Corán' del ár. süra.

adohar, 6r.28; 11v.13. Gay. addohar, adohar, 'la hora del mediodía y la oración canónica que se reza a esa hora'.

alayxi, 6v.13. Del ár. 'išà' 'oración vespertina'.

albarax, 10 v.5. Gay. lepra.

alcorán, 9r.12; 13r.2. Gay. 'Corán, Curán': El libro por excelencia, el Corán'.

alfaqui, $7 \mathrm{r}$.16. Alfaquí, jurisconsulto, versado en leyes'.

alacademe, 6v.1. Del ár. 'alá qadam, 'en pie, de pie'.

alfadilas, 11r.14. plu. cast. de alfadila. Gay. 'virtud, provecho, utilidad', del ár. fadila.

alguaçia, 10v. 15-16, 19. ?Encargo, recomendación, consejo', del ár. wașiyya.

alguado, 6r.23. Gay. alguaddo: 'lavatorio, ablución' del ár. wudu.

alhaçanas, 9r.3; 13v.16 y alhoçanas, 6v.28. del ár. ḩasana, alḩ̣osana. 'Acción meritoria, obra buena'.

alhaj, 6v.1. Gay. 'Peregrinación a la Meca', del ár. haŷŷy.

aljama, 6v.30; 7r.16; 10r.22. Gay. alchama, alchamaa, alxamaa.

'Reunión, aljama de moros del ár. ŷāma'. También significa mezquita principal, donde se reúne la aljama.

aljana, 7r. 24-26; 12v.5; 13v.7. Gay. alchanna, alchena 'el paraíso', del ár. yanna. aljanas plu. cast. de aljana $7 \mathrm{r} .1$.

almalayca, 7v.15. plu. de almalak 'ángel'. almalaycas 6v.5,7; 13r.9-10; 17; 13v.4. plu. cast. de almalayca.

almoçiba, 8r.15; 10r.1. Gay. almossiba 'desgracia, calamidad' del ár. mușíba.

alorxe, 7r.22. Del ár. 'ars 'trono, solio'

alydan, 11v.19. Gay. alydén, alidzán: pregón, convocatoria que se hace en la parte exterior de las mezquitas para que el pueblo acuda a la oración, del ár. 'idān.

anabi, 6r. 14; 10v.19. El profeta. del ár. nabí.

arracas, 10v.23; 12r.23. Gay. arraca: Cierta postura de la azala que consiste en inclinar el cuerpo hacia delante hasta tocar las rodillas con las palmas de las manos, del ár. raka'a.

arracares, 12v.25. Gay. arraquear verbo castellanizado en el sentido de 'hacer racas o arracas.'

arrayhan, 11r.12. Arrayán del ár. rayhanan.

arramadan, 6v.27; 7r.3. Gay. Ramadhan, noveno mes del calendario musulmán, en el cual se ayuna del ár. ramadän.

arrizque, 10v.9; 13r.12. Gay arrizuque, don sustento, alimento que envía Dios, del ár. rizq. Variante arrizaque, $11 \mathrm{v} .4$.

atahor, 13r.29. Gay. Purificación. del ár. țahāra.

axaytan, 7r.10,12; 9r.6; 10v.2; 11v.14; 12r.19; 13v.26. Del ár. šayțān.

axaytanes, $13 \mathrm{r}$.13. plu. castellảnizado de axaytan 'el demonio'. 
azaque, 6v. 25; 8v.3. Gayangos azaque, azaqui. Diezmo, limosna decimal del ár. zakāt. azabor, 9v. 12. del ár. zabūr 'salmo'.

azine, 10v; 12r. 14. Gay. alzine, azine, 'fornicación, adulterio' del ár. zinā çadiq, 8r.1.

çahor, 6v.15. Comida de madrugada (en Ramadán).

çalih, 8r.1. Gay. çalhe, çalihe, 'hombre bueno y de santa vida'.

çobhe, 6v.13. Oración de la madrugada, del ár. șobh.

fuzia, 11r.22. Del ár. faza' 'temor, miedo'.

Gabril, 6v.16. Gibril, 7r.15, 21, 23; 9r,11; 10v.16. El ángel Gabriel.

gihanam, 6v.13; 7r.2,27. Gay. chehennam, cihanam 'infierno' del ár. ŷihannam.

halel, 8r.7; 11v.15; 6r.8; 8v.17; 10r.21; 13r.31. helel 13r.3. Gay. Halel, halil, halyl: lo lícito, permitido; es lo contario de haram, del ár. halil.

haram, $83.7 ; 10 \mathrm{r} .9 ; 10 \mathrm{v} .28 ; 12 \mathrm{r} .15,16 ; 13 \mathrm{r} .6,12,31 ; 13 \mathrm{v}$. 13. Gay. haram, ilícito, nefando, lo que la ley y religión prohíben, del ár. haram.

harremó, pret, ind. de un verbo castellanizado procedente de haram. Gay. haramar, harramar: Prohibir, vedar, decir: " tal cosa sea haram".

hazalegero, 10v.22. El descreído "menos menor".

majid, 12r.21. Gay. almachid, almagid; mezquita, del ár. masŷid.

Muça, 10v.18. Moisés.

muçlim, 6r.8; 12v,1; 18. Musulmán. muçlimes e muçlimas, 7v.7. Plu. castellanizado 'musulmanes y musulmanas'.

Mycayl, 9r.11. Miguel (arcángel).

xaagual, 7r.3. Mes de šawwã.

$x a h y d, 10 v .21$. Gay. cháhid 'el que muere peleando y mártir de la fe' del ár. ȳāhid.

Yacob, 9r.12. Jacob.

Ybrahim, 9r.11. Abraham.

Yçhaq, 9r. 12. Isaac.

Yçrafil, 9r.11. Israfil, ángel del día del Juicio.

$Y_{\text {çrayl, } 9 \mathrm{r}, 11 \text {. Israel. }}$

Ysmayl, 9r.12. Ismael.

Palabras del castellano mudéjar toledano:

abanjello, 9r.12. Evangelio.

abasta, 11r.5. Ant. de bastar 'ser suficiente'.

adolmado, 10v.26. Adormir (del lat. adormire de ad y dormire), ant. 'dormirse'.

adolme, 10v.26. V. adolmado.

albriçialos, 13v.7. albriciar 'Dar una noticia agradable'.

allego, 11r.3. allegar ant. solicitar, procurar. Acercar.

apocare, 6r.12 apocar fig. limitar, estrechar.

arrepentençia, 12v.9. 'arrepentimiento'.

cata, 10v.28; 11r.7. Mirar, fijar la vista en un objeto.

catorzeno, 7r.29. Decimocuarto. 
cobdiçioso, 10r.9. Deseoso.

contentaçion, 12v.22. Contentación. (De contentar) ant. Contento, alegría, satisfación. danificar, 10r.29. Vulgarismo de damnificar. Causar daño.

debdo, 10r,14. Forma antigua de deudo.

desafuzia. 10v. 9-10. Ant. desahuciar. Quitar a uno toda esperanza de conseguir lo que desea. doblas, 13v.22. Moneda castellana de oro, acuñada en la Edad Media.

enblanqueçera (la cara), 7r.30. Sentido figurado, purificar, limpiar (el alma).

encomendanças, 6r.6. Ant. Mandamiento.

enfia,10r.4. Enfiar. Ant. Salir fiador de otro. Ant. Confiar firmemente en uno o en algo.

ensaña, 12v.22. Ensañar. Irritar, enfurecer.

ensordó, 11r.1. Ensordar. Forma ant. hoy ensordecer. Ocasionar o causar sordera.

escapame, 9v.13. Librame.

escosga, 6v.9. Escoger.

estenençia, 12v.10. ¿abstinencia?

farto, $12 \mathrm{v} .20$. Ant. harto.

gualardon, 6r.30; 7r.4; 7v.20. Galardón (de gualardón). Premio o recompensa de los méritos o servicios. gualardones, $12 \mathrm{v} .19$.

guarte, 10v.7; 11r.17. Interj. ¡Guárdate! ¡Guarda!

guisa, 12r.4. (Del germ. wisa). Modo, manera o semejanza de una cosa.

lyevan, 13v.4. Llevar, cobrar, exigir, percibir el precio o los derechos de una cosa.

la luvya de la abestuz, 11r.6. ant. lluvia. En otro manuscrito que aquí no se estudia dice: La lurya del guevo del abestruz, 26r. 16-17. hace suponer que luoya en este caso equivalga a clara de huevo.

medro, 8v.7. Medroso; temeroso, pusilánime, que de cualquier cosa tiene miedo.

melezina, 10v. ant. y hoy vulgarismo, medicina.

mençojero, 10v. 5-6. Meyer-Lübke 5509. 'mentiōnia 'mentira', mentiroso.

menoscabar, 6v.12. Disminuir las cosas quitándoles una parte.

masturar, 8r.6. Ant. revelar, descubrir o publicar uno el secreto que se le ha confiado.

morras, 10v.21. Futuro antiguo del verbo morir.

olvidança, 12v.7. Olvidanza (de olvidar) ant. olvido.

pagado, 11r.15. Pagado: que se paga o ufana de una cosa.

quinzeno, 7r.29. Decimoquinto.

rreboca, 11r.9. Revocar. Apartar, retraer...

rrogaria, 13r.8. Rogaria, ant. Ruego, súplica.

saña, 12v.23; 13r.12. (Del lat. sanna, mueca, gesto). Furor, enojo ciego.

sey, 11r.15. Imperativo ant. de ser.

sogudgado, 10v.26. Sojuzgado part. de sujetar; dominar, mandar con violencia.

terzeno, 7r.29. Decimotercero.

testemunio, 8v.16. vulg. de testimonio. Atestación o aseveración de una cosa.

vagaroso, $10 \mathrm{r} .6$ ant. tardo, perezoso.

vala vos del ..., 11r.2. Vala vos, apócope anticuada de valga con el sentido de descuidado con. 


\section{APÉNDICE DOCUMENTAL}

Hojas sueltas numeradas.

(f.6r.) 1 ya 'Ali non averguençes nyn rretraygas nyn blasfemes 2. de otro, que non ay carne syn tacha, e non se remyde el pe- 3 . cado del maldezir blafemear fasta que pidan perdón 4. aquellos que dixeron mal de él o le perdone. Yā 'Alī quando te hon- 5 rrare con quatro cosas, non te falleçerá nada, que uses 6 . verda en tu fabla, e guardes las encomendanças, e 7. seas franco del alma, e fanbriento de vientre. Yā 'Alī, 8., busca los bienes de deue todo muçlim, 9. Yầ 'Alí guarte de posarte cabo los muertos, que 10. ellos non nonbran sy non en lo que atañe al mundo, dixo 11. quien son los muertos, o mensajero de Dixo, los rricos que son 12. la conpaña deste mundo, que tienen sus coraçones en él 13. estos son los perdidos. Yã 'Alī sey sabio e deçiplo e pre- 14. gunta por tu ley, e non seas como dixo e dixo el anabi, 15. la salvaçión sea sobre él, que el que non sabe nyn aprende, nyn 16. demanda a los sabios por su ley está (ilegible) es perdido. Yà 'Alī 17. malo es el amigo que descubre tu secreto e dize lo malo 18. de ti, non a bien (roto) vezino que encubre tus buenas obras 19.. e descubre tus malas, e non a bien en muger que cobdiçia 20. quitarse de su marido. Yầ 'Alī faz conplidamente 21. tu alguado e demanda perdón a e non gastes mucha 22. agua. Yā 'Alī quien fará (palabra tachada) açala sobre Muhamad 23. e después de su alguado que diga: 24. 25. que quieren dezir: Apiade sobre Muhamad e sobre los 26. de Muhamad esparçiará su coraçón e oyrá su rogaria 27 . Yā Alī guarda el açala de adohar en camino o en villa, 28. que el día del juyzio oyrán que dirán ençima de las alturas 29. del aljanna: O fazedores del açala de adohar, con salvaçión, seguros, e faz 30. açala con el aljama e avrás tanto gualardón como. 